\title{
A CONCEPÇÃO NORMATIVA DO PROGRESSO SEGUNDO CONDORCET
}

\author{
Sidney Reinaldo da Silva ${ }^{1}$
}

Resumo: O texto mostra como, na filosofia de Condorcet, a arte social, o agenciamento político, se orienta pela norma do progresso. Argumenta-se que a normatividade associada ao conceito de progresso, como fato e valor, é imanente, ou seja, não se define como um dever ser idealizado ou modelo de perfeição orientador da decisão, mas como o que melhor será num contexto de aperfeiçoamentos acumulados e a se realizarem.

Palavras-chave: Condorcet - arte social - progresso - normatividade - imanência.

\begin{abstract}
Chamarei de concepção prospectiva do progresso o 'progresso como imperativo' e concepção retrospectiva o 'progresso como 'fato'2
\end{abstract}

Nós julgamos em nome de certa noção de progresso humano. Quem nos garante que essa noção é correta?3

Uns imitando Platão, tais como Morus e Hobbes, deduziram de alguns princípios gerais o plano inteiro da ordem social, e apresentaram o modelo do qual a prática constantemente devia tender a se aproximar. Outros, como Maquiavel, buscaram no exame profundo dos fatos da história as regras segundo as quais se poderia dominar o futuro. 4

A filosofia do Marquês de Condorcet (1743-1794) continua sendo uma referência atual, sobretudo numa época em que, o progresso como ideologia ou pelo menos como um tema de propaganda reaparece no cenário político nacional ${ }^{5}$. Mas diferentemente do modo como

\footnotetext{
${ }^{1}$ Doutor em Filosofia pela Unicamp (1999) sob orientação do Prof. Dr. Roberto Romano da Silva. E-mail: sidney.silva@ifpr.edu.br

2 ALLEN, The End of Progress: Decolonizing the Normative Foundations of Critical Theory, p. 12. (As traduções dos textos estrangeiros citados neste artigo são de responsabilidade do autor)

${ }^{3}$ BARDÈCHE, Maurice. Nuremberg ou la Terre Promise, p. 14.

${ }^{4}$ CONDORCET, Esquisse d'un tableau historique des progrès de l’esprit humain, p. 201

${ }^{5}$ Cabe lembrar que com a crise da ideia de progresso durante o Século XX, o otimismo condorcetiano foi relegado à condição de mero desvario ou ilusão, tendo relevo mais o seu contrário, à crença na decadência
} 
positivistas empregam o termo progresso, Condorcet imuniza o seu significado contra usos legitimadores de regressões sociais ${ }^{6}$. O tema torna-se ainda pertinente frente ao que se presencia hoje em escala global relativo aos retrocessos em termos de valores democráticos, liberdade, igualdade e respeito à dignidade humana.

A obra de Condorcet ganha nova visibilidade frente a enfoques metodológicos contemporâneos nas mais diversas áreas do conhecimento. De modo especial, a sua concepção de progresso e de decisão coletiva são sempre reinterpretadas7. O presente texto almeja fazer uma abordagem do tema progresso em Condorcet levando em conta certas possibilidades abertas pela revitalização do enfoque teórico-normativo do progresso $^{8}$. Com isso evitam-se as leituras reducionistas da ideia de progresso condorcetiana, formas de apresentá-la como meramente determinista, mecanicista, linear, utopista acrítica e, especialmente, protopositivista. $\mathrm{Na}$ ótica do filósofo francês, embora o aperfeiçoamento humano seja irresistível, ele não deixa de ser combatido, atrasado e estagnado. Pode-se mesmo falar de um curso sinuoso de sua concepção de progresso9. De qualquer modo, para o autor, a investigação do progresso visa conhecer como um valor melhor se realizou, se realiza ou pode se realizar. Isso condiz com o atualizado postulado de que na perspectiva do participante, o ser humano tende a ver a si mesmo como capaz de se aperfeiçoar ${ }^{10}$.

Condorcet, a seu modo, focou o progresso como um imperativo moral, como razão para agir e superar obstáculos à "melhoria" da vida individual e coletiva e para a criação de condições

dos povos, na sua degeneração (HERMAN, The Idea of Decline in Western History) ou na regressão à "barbárie".

${ }^{6}$ Cf. KRYNSKA, S. Entwicklung und Fortschritt nach Condorcet und A. Comte.

7 Para uma contextualização da ideia de progresso em Condorcet, ver: IGGERS, The Enlightenment Idea of Progress Revisited. Sobre a relação entre história e natureza do progresso, ver: BOARINI, Turgot, Condorcet. Les Lumières face an progrès. Para a questão dos valores e suas implicações na decisão coletiva, ver ROTHSCHILD, Condorcet and the Conflict of $V$ alues.

8 A atualização de Kant e Hegel no âmbito da teoria da justiça foi acompanhada pela reafirmação do teor normativo do progresso. Allen, indo além das abordagens modernas, propõe uma leitura "descolonizante" do progresso, num esforço de resgatar o seu valor no interior da própria teoria crítica. Esse movimento conhecido inicialmente pela dura crítica à violência do progresso e sua guinada regressiva, tornou-se também uma base para pensar o progresso não pelo outro, mas com o outro. (Cf. ALLEN, The End of Progress: Decolonizing the Normative Foundations of Critical Theory).

${ }^{9}$ WALDINGER, R. Condorcet: The problematic nature of progress.

10 Trata-se de enfocar o progresso como "[...] resultado de um processo de aprendizagem e, portanto, não sendo nem meramente convencional nem baseado em alguma concepção a priori ou transcendental de razão pura. Essa orientação normativa, por sua vez, nos oferece uma concepção de sociedade boa ou mais justa que proporciona a base para nossas batalhas moral-políticas." (ALLEN, The End of Progress: Decolonizing the Normative Foundations of Critical Theory, p. 14). Para Condorcet, a necessidade do progresso se deve a forma como o seu valor incorpora-se como algo irrecusável na formação da razão e da moral de um povo, sobretudo com a instrução pública. 
capazes de garantir o aperfeiçoamento da humanidade. Nesse sentido, o progresso remete à questão de como identificar e exigir um estado de coisas e/ou modo de ser melhor. Relativo a esse debate encontra-se atualmente uma discussão profícua sobre a existência ou não de um padrão transcendental para estimar (medir, calcular, avaliar e desejar) o melhor, ou se isso não é necessário, bastando apenas comparar as possiblidades em jogo entre si para se escolher o preferível ${ }^{11}$. Da mesma forma, apresenta-se a questão sobre quem está autorizado a definir o que é melhor para a humanidade ou para uma coletividade.

No âmbito da teoria crítica isso também reaparece. Assim surgem abordagens sobre a natureza da base normativa, seja quando ela é tomada como transcendente, caso em que os princípios universais de justiça são dados, quer por um acesso especulativo supostamente privilegiado à verdade moral ou por meio de procedimentos hipotéticos/dedutivos imparciais, ambos presumindo, cada um à sua maneira, a legitimidade para propor, de modo descontextualizado, princípios exigíveis universalmente ${ }^{12}$. Por outro lado, considera-se a base normativa como imanente quando ela decorre da reconstrução de valores historicamente preponderantes numa determinada sociedade cujas promessas não cumpridas ou parcialmente realizadas, continuam, contudo, sendo capazes de orientar as decisões sobre a justiça social ${ }^{13}$. A relação entre imanência e transcendência é sempre desafiadora frente à indagação de como ir além do que se tem, tanto no sentido de universalização de valores quanto no de formas de convivência social, frente a um referencial teórico e prático contextualizado. Essa perspectiva crítica é posta como um pano de fundo para discutir a questão da normatividade do progresso em Condorcet, sobretudo para uma abordagem não reducionista de seu pensamento, como aventada acima.

11 Uma teoria transcendental da justiça "concentra sua atenção no que ela identifica como justiça perfeita e não em comparações relativas de justiça e injustiça. Pretende-se apenas identificar características sociais que não podem ser transcendidas em termos de justiça, e seu foco, dessa forma, não está na comparação entre sociedades possíveis, todas longe do ideal de perfeição. A investigação procura assinalar a natureza do 'justo', e nenhum critério é buscado para identificar uma alternativa como menos injusta que outra." (SEN, 2009, pp. 5-6). Contudo, dentro da tradição da teoria da escolha social, questiona-se também até que ponto é possível comparar alternativas sem um padrão transcendental. (EGE, IGERSHEIM, LE CHAPELAIN. Transcendental vs Comparative Approaches to Justice: A Reappraisal of Sen's Dichotomy).

12 Sobre a estratégia de justificação associada ao universalismo descontextualizado e críticas a ela ver FORST, Kontexte der Gerechtigkeit: Politische Philosophie jenseits von Liberalismus und Kommunitarismus.

${ }^{13}$ Honneth, no contexto da teoria crítica, expressa com precisão essa perspectiva: "Os padrões nos quais semelhante forma de crítica se apoia nada mais são que aqueles tomados como princípio orientador pela reconstrução normativa; como instância da eticidade, eles representam valores ou ideias gerais através de um conjunto de práticas institucionalizadas, e podem, então, ser usados também para criticar as práticas estabelecidas como ainda não adequadas em relação ao seu desempenho representativo. Em tal 'crítica reconstrutiva', as instituições e práticas não são, portanto, contrapostas a simples padrões externos; pelo contrário, os mesmos padrões através dos quais aquelas foram primeiramente destacadas do caos da realidade social são usados para reprovar a forma ainda defeituosa e incompleta como os valores geralmente aceitos foram incorporados." HONNETH, Das Recht der Freibeit: Grundriß einer demokratischen Sittlicbkeit, p. 28. 
A obra de Condorcet é anterior a moderna base do pensamento crítico, contudo, ele também investigou as condições de possibilidade do progresso. Mas diferentemente de Kant, ele privilegiou uma abordagem a posteriori de fundamentação do progresso como um valor. Seu método apresenta-se mais como uma reconstrução prospectiva do progresso. Como eixo de uma democracia epistêmica, em Condorcet, a passagem do progresso passado para o progresso futuro funda-se em uma combinatória, ou seja, no poder da análise, do cálculo matemático como instrumento das ciências e do rigor na apuração do motivo de crer que o futuro será melhor que o passado. O pensador francês, diferentemente de Kant, não concebeu uma razão prática formalista despregada do conhecimento científico, mas sim uma correlação teoria e prática na qual as ciências morais operam como as ciências naturais ao aplicar seus princípios à arte, à técnica. Ainda nesse sentido, o juízo moral dos indivíduos dependeria do estofo do conhecimento, do agenciamento contínuo da verdade na forma de instrução pública.

Dificilmente se poderia estabelecer correlações diretas entre as obras de Condorcet e a tradição inaugurada pela filosofia crítica kantiana. Conduto, a questão do progresso será sempre um tema que remete a Condorcet, mesmo quando não se menciona esse autor para discuti-la, tal como ocorre na obra de Allen. ${ }^{14}$ Mas, de qualquer forma, a abordagem dessa autora enseja releituras da ideia de progresso em Condorcet, tornando-o um interlocutor relevante, sem, contudo, pretenderse com isso traçar linhas de influências ou de antecipações deste autor em relação a pensadores teórico-críticos. Nesse sentido, desponta-se sobretudo a abordagem de Honneth sobre o progresso do que a de Forster como mais capaz de iluminar a compreensão de certos aspectos da obra de Condorcet ${ }^{15}$.

Este texto visa delinear a normatividade do progresso na filosofia de Condorcet, mostrando, como, a seu modo, ele propôs uma concepção imanentista do valor da perfectibilidade. Defende-se que não está em questão o dever ser (como uma dada ideia reguladora aproximável, contudo inatingível), mas o como melhor será frente à perfectibilidade do próprio progresso, dos meios de atestá-lo e promovê-lo. Isso implica destrinchar três pontos entrelaçados em sua concepção de progresso: a) não há princípios transcendentes capazes de orientar a prática humana; b) o progresso vindouro decorre do que tem sido ou tende, inexorável (conforme a natureza humana e os fatos) e ao mesmo tempo programaticamente (de modo coletivamente agenciado), a ser melhorado; c) cabe à arte social descobrir, no rumo apresentado pelas coisas (progresso passado), o valor da

\footnotetext{
14 ALLEN, The End of Progress: Decolonizing the Normative Foundations of Critical Theory.

15 Allen aponta diferenças relevantes a esse respeito: para Honneth, "a noção de progresso histórico serve, pelo menos em parte, para justificar a normatividade dos princípios que encontramos em nosso mundo social"; Forst, ainda que afirme o enraizamento a contextos específicos do processo de justificação, evitando assim, ao mesmo tempo, o puro formalismo e o etnocentrismo, não deixa de remontar especialmente a Kant reafirmando que "a normatividade do princípio de justificação, que não é fundada historicamente mas nas demandas da própria razão prática, oferece o padrão segundo o qual juízos sobre o processo histórico (ou regresso) podem ser feitos." (The End of Progress: Decolonizing the Normative Foundations of Critical Theory, p. 124.)
} 
perfectibilidade, segundo o qual serão combatidos os retrocessos, evitados retardamentos e avançado o processo de aperfeiçoamento ${ }^{16}$. Defende-se, no presente texto, que em Condorcet a uma forma específica de abordagem da passagem entre os progressos pretéritos e os progressos futuros: o valor do progresso revela-se nas práticas de seu agenciamento, no modo como o conhecimento dos aperfeiçoamentos como fato mostra os fins e os meios para se promover os progressos futuros. A imanência diz respeito a esse modo como o valor do progresso se mostra na prática do seu agenciamento.

O âmbito dessa investigação restringe-se ao modo como na Esquisse d'un tablean historique des progrès du esprit humain (Esboço de um quadro histórico dos progressos do espírito humano), doravante Prospecto ${ }^{17}$, reconstroem-se os valores da perfectibilidade ${ }^{18}$. Nessa obra, Condorcet, em 1793, ano de sua proscrição, expõe a marcha do espírito humano, mostrando que, ao progredir, a humanidade descobre o que é o progresso, como progredir e por que se deve progredir. Contudo, para mostrar a correlação entre as ciências morais e políticas, a naturalização do espírito e o progresso, foi retomado o texto Discurso de recepscão à Academia Francesa19, escrito por Condorcet em 1782.

A presente abordagem ressalta os seguintes pontos: i) a perfectibilidade (e o progresso como sua manifestação) como índice de si mesma; ii) o conhecimento e avaliação do progresso no âmbito das ciências morais (políticas, sociais) frente à naturalização do espírito; iv) o agenciamento dos progressos como realização e abertura do campo da perfectibilidade.

\section{A perfectibilidade do progresso}

Questões ligadas ao valor do progresso foram acuradamente tratadas por Condorcet, em sua filosofia da perfectibilidade humana. Segundo ele, o progresso indefinido ${ }^{20}$ fundamenta uma justiça comparativa ${ }^{21}$, ou seja, legitima-se como guia da decisão coletiva. Isso refere-se ao modo

\footnotetext{
${ }^{16}$ Nesse sentido, apresenta-se aqui o modelo normativo do progresso em Condorcet como uma articulação dos modi operandi platônico e maquiavélico de investigação da prática política fazendo com que um corrija o suposto equívoco do outro, respectivamente, o excesso de idealismo e de realismo. Sobre o modo como o filósofo francês identifica esses modelos vide o cabeçalho do presente artigo.

${ }^{17}$ Condorcet referiu-se à Esquisse como um Prospectus para indicar que se tratava de uma síntese apresentando uma obra mais vasta que comporia o quadro dos progressos do espírito humano.

${ }^{18}$ São apontadas três exigências fundamentais: "a destruição de desigualdade entre as nações; os progressos da igualdade em um mesmo povo; enfim, o aperfeiçoamento real do homem" (CONDORCET, Esquisse d'un tableau historique des progrès de l'esprit bumain, p. 194).

${ }^{19}$ CONDORCET, Oeuvres, Tome I, 1968.

${ }^{20}$ Sobre a polêmica entre progresso indefinido e infinito, bem como sobre a perfectibilidade como objeto e finalidade das ciências morais ver BINOCHE (Org). L'homme perfectible.

${ }^{21}$ Esse enfoque foi destacado sobretudo depois que Amartya Sen identificou a abordagem da justiça de Condorcet como comparativa, contrapondo-a ao enfoque transcendental da mesma. Cf. SEN, The Idea of justice, p. xvi.
} 
como ele concebe que não há nada de permanente e invariável no espírito humano a não ser a disposição de suas faculdades ou capacidades para o aperfeiçoamento. Nesse sentido, não se reconhece nenhum ponto fixo como referência avaliativa final ou limite para os seus próprios progressos: "não foi marcado nenhum limite ao aperfeiçoamento das faculdades humanas [...]; a perfectibilidade do homem é realmente indefinida" 22. No Prospecto, destaca-se como permanente que os homens, com o tempo, adquirem ideias morais, e, como variável quais ideias são adquiríveis, o que daria ao futuro um caráter dramático, pois os valores guias da humanidade são ajustáveis conforme esta progride.

Como referência normativa axial, o progresso exige a concentração de esforços para ser conhecido e promovido. Isso é o que faz Condorcet com no Prospecto. Nesse texto, a investigação das condições de aperfeiçoamento como tarefa filosófica justificou-se frente ao risco de estagnação da perfectibilidade coletiva e da decorrente perda dos progressos já conquistados e dos vindouros. A filosofia torna-se, sobretudo, o exercício vigilante das faculdades humanas no conhecimento (da verdade e da validade) de seus próprios progressos.

$\mathrm{Na}$ filosofia de Condorcet, a perfectibilidade indefinida é posta como modo de ser humano, constituindo-se também em seu próprio fim, ou seja, o aperfeiçoar-se como um bem em $\mathrm{si}^{23}$. Nisso há paradoxal circularidade: como princípio imutável, na forma de conditio sine qua non da constituição humana, a perfectibilidade rege a si mesma e, ao fazer isso, ela nega sua própria imutabilidade ${ }^{24}$, pois, enquanto valor, ela também está sujeita a progressos. Assim ideias morais tomadas como princípios normativos condizentes com a natureza (integridade, constituição) humana só puderam surgir em momentos propícios ao seu florescimento, aperfeiçoando-se com os progressos do espírito humano. Uma descrição paradigmática disso é o modo como o valor da abrangência universal da liberdade e da igualdade só pôde ser afirmado com os progressos

${ }^{22}$ CONDORCET. Esquisse d'un tableau historique des progrès de l'esprit humain, p. 81.

23 Os progressos mais variados realizados pelas atividades humanas têm como escopo (terme) a própria perfectibilidade. (CONDORCET, Esquisse d'un tableau historique des progrès de liesprit humain, p. 277). A esperança, ou seja, o valor da perfectibilidade, decorre do exame (que lhe dê uma certeza moral ou expectativa baseada no número, na frequência e na exatidão das observações) da "cadência" (marche) e das "leis desse aperfeiçoamento" (Idem). O progresso no Prospecto enquadra-se na tradição empirista (Cf. WILLIAMS, Progress and the Empirical Tradition in Condorcet).

${ }^{24}$ Depois de mostrar que a perfectibilidade humana é indefinida, tal como os progressos observados e o modo de operar das faculdades humanas indicariam, Condorcet aponta para a possibilidade aberta de aperfeiçoamento das próprias condições do aperfeiçoamento humano: “(...) até aqui, nós supomos os homens como tendo as mesmas faculdades naturais, a mesma organização. Quais seriam, portanto, a certeza, a extensão dessas esperanças, se pudermos crer que essas próprias faculdades naturais, essa organização, são também susceptíveis de melhoramento, trata-se da última questão que nos resta examinar." (CONDORCET, Esquisse d’un tableau historique des progrès de lesprit humain, p. 293) 
efetivados na Nona Época do Prospecto. Os valores são conhecidos com o processo de realização e aperfeiçoamento dos mesmos:

Os homens não poderão conhecer a natureza e o desenvolvimento de seus sentimentos morais, os princípios da moral, os motivos naturais de agir conforme estes, seus interesses, seja como indivíduo, seja como membro de uma sociedade, sem fazer também progressos na moral prática não menos reais que os realizados própria pela ciência. 25

Tal como a verdade, o valor da perfectibilidade, a crença de que ele se efetiva, vem com o tempo, sua hora chega quando os fatos são conhecidos em grandes números de modo a oportunizar o pronunciamento da razão. Segundo Dagen 26 "a Minerva das Luzes não nasce armada e já com seu elmo", o valor do progresso não escapa a isso, pois a ideia de perfectibilidade demeure perfectible (permanece perfectível).

O quadro histórico dos progressos, o Prospecto, calcado em fatos e na reflexão, pretende mostrar a perfectibilidade em movimento como um valor já efetivado e ainda por se efetivar. Isso remete à declaração normativa de que se a perfectibilidade é fato, então ela deve ser aceita como um princípio. Mas Condorcet, a seu modo, evita a falácia naturalista, pois o valor normativo (dever ser) não decorre meramente do que é, mas também do que será. O que prova a perfectibilidade não são apenas os progressos efetivados, mas os que, com segurança, podem ser tomados como efetiváveis. O seu valor decorre de sua verdade, sendo relativo à natureza probabilística desta27. A questão está em como averiguar e estimar a conexão entre o que foi e o que será progresso. Do ponto de vista da (razão, moral) prática, o melhor é tomado como uma escala relativa, aperfeiçoável, pois ele depende do equacionamento dos fatores do progresso em cada momento específico, o que torna atividade normativa semelhante ao trabalho de re/construir a embarcação em alto-mar.

Seria, portanto, uma restrição ao peso normativo do progresso subordiná-lo a uma escala de valores absoluta. Nesse caso, o melhor é tomado como relativo a um valor fixo que serve para escalar as alternativas do preferível. Mas tais valores deveriam ser tão bem-acabados que se tornariam

${ }^{25}$ CONDORCET, Esquisse d'un tableau historique des progrès de l'esprit bumain, p. 285.

${ }^{26}$ DAGEN, J. L’histoire de l'esprit humain dans le pensée francaise: de Fontenelle à Condorcet, p. 615.

${ }^{27} \mathrm{O}$ ceticismo de Condorcet abrangia até mesmo o conhecimento matemático: "Nota-se que uma proposição matemática como, por exemplo, ' $2+2=4$ ', é intuída como correta. Mas podemos ter certeza de que nossas mentes continuarão a funcionar da mesma maneira, de modo que a proposição assemelhar-se-ia como certa no futuro? O tipo de dúvida que Condorcet estava levantando é algo como o ponto levantado por Hume em seu Treatise, posicionando o ceticismo de modo crítico às características intrínsecas do funcionamento da razão. Condorcet parece ter sido o único dos philosophes que leu o Treatise e o único que conhecia o ceticismo de Hume com relação à matemática. A matemática tornou-se então levemente duvidosa e, de alguma maneira, empírica (dependendo da continuidade do modo pelo qual a psiqué humana opera). A matemática, assim como a física e as ciências morais, seriam apenas uma probabilidade." (POPKIN, Novas considerações sobre o papel do ceticismo no Iluminismo, p. 76) 
insusceptíveis de aperfeiçoamento, frente aos quais o progresso não seria o valor maior. Mas quando se toma o progresso como valor absoluto, a exigência de progredir justifica-se por si própria; passa a valer o progredir pelo próprio progredir, não cabendo satisfazer-se com o bem, mas com o melhor. Afirmado como bem em si, o progresso é elevado à categoria de fonte última de legitimação, frente à qual toda justificação relevante deve se subordinar. Perante isso, mesmo a aceitação da proposição nem toda forma de progresso é sempre válida moralmente acarreta necessariamente a negação da tese do progresso como valor absoluto, pois como índice de si mesmo, o crivo avaliativo do progresso também está sujeito à perfectibilidade, sendo também avaliado conforme se progride ou não.

Para Condorcet, frente às exigências do progresso, às ciências morais (políticas, sociais), tomando o homem (espírito humano) como um ser natural, é apresentado um duplo desafio: manter o rigor nos estudos dos fatos relativos aos progressos e apontar para o que é desejável, tanto no sentido de viabilidade quanto de validade para ser realizado ${ }^{28}$.

\section{Naturalização do espírito humano e o estatuto das ciências morais}

A naturalização do espírito humano é correlata de uma abordagem dos fenômenos morais no mesmo âmbito de determinação dos fatos naturais, isso tornou-se uma das principais características do materialismo francês do Século XVIII ${ }^{29}$. A distinção entre o físico e o moral foi mais uma questão de conhecimento adequado do que de diversidade ontológica ${ }^{30}$. Não há, partindo desse pressuposto, razões para se diferenciar epistemologicamente ciências naturais e morais no modo como se deve conhecer a necessidade do progresso. ${ }^{31}$

28 "Os fatos sobre os quais esses resultados se apoiam podem, sem cálculo e apenas conforme a observação, levar às vezes a verdades gerais, a conhecer se o efeito produzido por uma causa foi favorável ou contrário; mas se tais fatos não puderam nem ser contatados, nem pesados, se esses efeitos não puderam ser submetidos a uma medida exata, então não se poderá estimar o bem ou mal que resulta desta mesma causa; e se um e outro não se compensam com a mesma igualdade, se a diferença não é muito grande, não se poderá mesmo manifestar com alguma segurança de qual lado a balança pende." (CONDORCET, Esquisse d'un tableau bistorique des progrès de lesprit bumain, p. 284)

${ }^{29}$ Segundo D’Holbach, "O homem é um ser puramente físico; o homem moral é esse ser físico considerado sob um certo ponto de vista, isto é, relativamente a algumas formas de agir, devido a sua organização particular." (D'HOLBACH, Système de la nature ou des lois du monde physique et du monde moral, p. 6)

30 "Ocorre o mesmo com o homem que, em todos os seus progressos, em todas variações que experimenta, não age senão conforme as leis de sua organização específica e as matérias das quais a natureza a compôs. $O$ homem físico é o homem agindo pela impulsão de causas que nossos sentidos nos permitem conhecer; o homem moral é o homem agindo por causas físicas que nossos preconceitos nos impedem de conhecer." (D'HOLBACH, Système de la nature ou des lois du monde physique et du monde moral, p. 7)

${ }^{31}$ Esse modo de naturalismo associa-se a uma visão realista do progresso como valor. Sheehy apresenta da seguinte maneira essa correlação, a partir da qual, de certo modo, pode-se compreender o pensamento de Condorcet: "Se a moralidade é objetiva dessa forma, então faz sentido a ideia de progresso assim como a possibilidade de erro. Apontando para o paralelo com o progresso científico, o realista pode sugerir que as coisas podem melhorar moralmente conforme adquirimos conhecimento moral. Assim como a ciência 
No Prospecto, o natural e o moral são abordados como sendo de uma mesma categoria ontológica, acessíveis por meio de uma mesma forma de conhecimento ${ }^{32}$ e susceptíveis a aplicações e práticas análogas ${ }^{33}$. Admite-se assim que os "fatos morais" são "naturais". A constituição do ser humano é tomada de tal modo que o certo e o errado são dados, respectivamente, pelo sentimento de prazer e dor. Este sentimento pode ser presenciado tanto pela introspecção quanto pela observação das outras pessoas e mesmo dos animais ${ }^{34}$. Essa capacidade natural de sofrer perante a dor alheia e o desejo de amenizá-la é correlata da repugnância em causar sofrimento a outrem ${ }^{35}$. Causar sofrimento alheio, para os indivíduos não corrompidos, é "uma verdadeira impossibilidade moral e mesmo uma impossibilidade física, no caso de uma ação imediata e direta" ${ }^{6}$. Presume-se com isso que um sentimento de piedade e bondade é uma consequência necessária da organização natural do ser humano, sem o qual a espécie não teria se mantido. Contudo, essa afeição mútua pode ser quebrada quando os interesses de indivíduos e grupos se opõem. O progresso da moral e da justiça é observável ou promovido justamente quando as causas dessa oposição são desmontadas pela arte moral e social, como mostra o texto Fragmento da história da $X^{a}$ época do Prospecto.

A construção do Prospecto, obedecendo a exigência epistemológica da naturalização do espírito, é um empreendimento baseado em "fatos" e "raciocínios", visando avaliações prospectivas, ou seja, investigação de viabilidades. Como aponta Frick ${ }^{37}$, para Condorcet, quem

progride quando as teorias se aproximam mais e mais dos fatos relativos ao mundo natural, da mesma forma podemos progredir moralmente quando aumentamos o nosso conhecimento moral. É claro que a possibilidade de progresso moral e aperfeiçoamento por meio do aumento do conhecimento não quer dizer que o progresso será, suave, fácil ou sustentado. O ponto realista não é o de que estamos fazendo progresso moral inevitável, mas que há uma explicação disponível para o que significa referir-se a tal progresso." (SHEEHY, Moral Facts, p. 3)

32 "Assim a análise de nossos sentimentos nos faz descobrir, no desenvolvimento de nossa faculdade de sentir prazer e dor, a origem de nossas ideias morais, o fundamento das verdades gerais que, resultando dessas ideias, determinam as leis imutáveis, necessárias do justo e do injusto; enfim os motivos de agirmos conforme a elas, saídos da própria natureza de nossa sensibilidade, no que se pode chamar, de qualquer modo, nossa constituição moral" (CONDORCET, Esquisse d'un tableau bistorique des progrès de lesprit bumain, p. 223). Cabe lembrar que, para Condorcet, a constituição moral humana, objeto desse método reconhecido como de uso universal, é perfectível, suas faculdades agem sobre si mesmas e isso altera o modo pelo qual os sentidos são afetados.

33 A naturalização do espírito humano permite a correspondência entre aplicações das ciências naturais e morais. Cf. CONDORCET, Esquisse d'un tableau historique des progrès de l'esprit bumain, p. 286).

34 "As sensações são acompanhadas de prazer e dor; e o homem tem da mesma forma a faculdade de transformar essas impressões momentâneas em sentimentos duráveis, agradáveis ou dolorosos; de experimentar esses sentimentos na presença ou ao se lembrar de prazeres e dores de outros seres sensíveis" Esquisse d'un tableau historique des progrès de lesprit humain, $\mathrm{p} 79$.

${ }^{35}$ CONDORCET, Fragment de l'bistoire de dixième Époque, p. 543-4.

${ }^{36} \mathrm{Idem}, \mathrm{p} .544$.

${ }^{37}$ FRICK, Condorcet et le probleme de l'Histoire, p. 353. 
sabe calcular os lances (chances) poderá evitar combinações ruins e aproveitar as boas, as susceptíveis de o beneficiar. Frente à exigência de como o melhor deve ser conhecido, o correto refere-se às possibilidades de aperfeiçoamento contida em algo, o que demanda definir novas combinações das alternativas em jogo para melhorar certo arranjo dado.

O quadro aborda as ciências morais como se estas fossem susceptíveis ao mesmo rigor e "objetividade" presente nas ciências da natureza. A razão é a mesma, mudando apenas os objetos e a forma segundo a qual ela se aplica, seja teórica ou praticamente: a cada ciência corresponde uma arte. ${ }^{38}$ Nesse sentido as ciências humanas, cujo objetivo é a felicidade do homem, a descoberta da vida boa (feliz, virtuosa), poderão se submeter a procedimentos tão seguros quanto os aplicados às "ciências físicas". As ciências morais, afirma-se no Discurso de recep̧̧ão à Academia Francesa, "devem seguir o mesmo método, adquirir uma língua igualmente exata e precisa, atingir o mesmo nível de certeza" 39. Os fatos morais, tais como os fatos físicos, têm o mesmo estatuto observável. A este respeito afirma-se que "tudo seria igual entre eles para um ser que, estranho a nossa espécie, estudasse a sociedade humana como nós estudamos a sociedade dos castores ou das abelhas" 40 . Contudo há uma ressalva: no âmbito das ciências morais, "o próprio observador faz parte da sociedade que ele observa, e a verdade não pode ter senão juízes influenciados ou seduzidos" 41 . Essa participação faz com que em cada época, por mais que o espírito humano avance rumo à verdade, erros e preconceitos acabem surgido: "conforme as leis gerais do desenvolvimento de nossas faculdades, certos preconceitos tiveram que nascer a cada época dos nossos progressos." 42

Condorcet entende que os erros e preconceitos decorrem da sociabilidade humana: da comunicação e das relações de poder, da criação de estratégias de dominação pautadas no obscurantismo e no monopólio da comunicação por uma classe dominante. A interferência desvirtuada no conhecimento da verdade, a distorção da perspectiva do participante, aparece especialmente no modo como os erros surgem e o progresso é obstaculizado. Erra-se quando não se toma as decisões corretas exigidas pelo princípio do progresso. Frente à perfectibilidade, os homens não são meramente joguetes. Eles participam, corretamente ou não, podendo acelerar ou retardar avanços da razão, do conhecimento e da divulgação da verdade.

Com o erro, o espírito humano estagna-se ou aperfeiçoa-se de modo meramente pontual, desfazendo, muitas vezes, o elo entre uma sequência de progressos, que só com muito custo poderia ser restabelecido. Isso é uma condição inelutável com a qual as ciências morais e políticas devem lidar quando visam conhecer a perfectibilidade em movimento. Nesse sentido, o

\footnotetext{
38 As regras de uma arte decorrem dos princípios da ciência que lhe é correspondente. "A arte tem por objetivo combinar e escolher o que os princípios mostraram ser verdadeiro, justo e útil." (CONDORCET, Sur le sens du mot Révolutionnaire, p. 606)

${ }^{39}$ CONDORCET, Discours de Reception à l'academie française, p. 392

${ }^{40} \mathrm{Id}$., ibid.

${ }^{41}$ Id., ibid.

${ }^{42}$ CONDORCET. Esquisse d'un tableau historique des progrès de lèsprit humain, p. 87.
} 
conhecimento do progresso refere-se ao saber sobre um valor realizado. Progresso é, ao mesmo tempo, fato e valor e, enquanto tal, deve ser investigado para ser promovido. Segundo Condorcet, teria chegado o momento de uma guinada na perfectibilidade humana: os seres humanos passam de uma situação na qual faziam progressos sem corretamente o saber para uma forma consciente e agenciada de fazê-lo.

Da mesma forma como as ciências matemáticas e físicas servem para aperfeiçoar as artes empregadas para nossas necessidades mais simples, não ocorre igualmente na ordem necessária da natureza que os progressos das ciências morais e políticas exercem a mesma influência sobre os motivos que dirigem nossos sentimentos e nossas ações? 43

O "homem moral", em sua condição de perfectível, é capaz não apenas de analisar os impulsos e impressões recebidos exteriormente, mas também de refletir sobre o que sente e passar a agir com conhecimento das causas que atuam sobre ele. Isso passou a valer também para se pensar a dimensão coletiva da perfectibilidade. $O$ aperfeiçoamento, inicialmente um mecanismo cego, vai sendo conhecido e passa a ser regulado. Desvencilhando-se do erro e de preconceitos, a arte social, meio da perfectibilidade coletiva, passa a promover os progressos dos povos, formando e, ao mesmo tempo, sendo redefinida pela razão pública, ou seja, a razão e a moral de um povo, a razão comum, nos modos de dizer de Condorcet.

\section{Perfectibilidade e agenciamento do progresso: a arte social}

Condorcet apresentou a perfectibilidade como condição ontológica do ser humano e a estatuiu como modelo normativo capaz de orientar a definição do bem e mal do ponto de vista da coletividade. Contudo, o que fez esse filósofo, no contexto da Revolução Francesa, foi reafirmar a pertinência e a necessidade da ideia de perfectibilidade para a abordagem de questões ético-políticas, tais como: por que levar em conta o progresso quando se decide sobre o que devemos fazer ou exigir uns dos outros? Devemos aceitar alguma obrigação política, imposição coletiva ou governamental, em seu nome? Essas questões despontam na sua avaliação dos progressos ou regressos efetivados pelos povos, base empírica e moral para o estudo da perfectibilidade futura do espírito humano ${ }^{44}$.

${ }^{43}$ CONDORCET, Esquisse d'un tableau historique des progrès de l'esprit humain, p. 286.

${ }^{44}$ Há quem defenda que, em Condorcet, não se trata propriamente da história em seu sentido moderno, como processo de autodesenvolvimento de si do ser humano através do tempo, mas como um esforço de aperfeiçoamento de um mesmo estado original: "Para Condorcet, a história não é senão o meio que permite a humanidade perfilar (profiler) cada vez mais nitidamente em sua silhueta original, graças a ação de múltiplas circunstâncias que transformam as condições de sua manifestação em um sentido mais e mais favorável, 
A necessidade de progredir refere-se às exigências práticas da vida relativas ao indivíduo e à comunidade. A percepção de uma necessidade sem um objeto adequado para satisfazê-la é condição para o aperfeiçoamento, ou seja, a descoberta de um novo arranjo de progressos disponíveis visando melhorar uma situação. $\mathrm{Na}$ dinâmica da perfectibilidade humana, aperfeiçoamentos anteriores sempre produzem necessidades novas que exigem novos progressos ou proporcionam a criação de novas possibilidades antes imperceptíveis ${ }^{45}$. Assim surgem exigências de patamar superior que impulsionam o espírito humano rumo à compreensão do melhor e à produção do conhecimento e da arte específicos para influir na marcha dos progressos ${ }^{46}$.

Há dependência entre um progresso e outro, pois determinados progressos são necessários para que outros ocorram: “[...] cada momento presente depende do que foi proporcionado pelos momentos passados e influi sobre os instantes dos tempos que devem seguir" "47. Contudo, do fato de certas condições (aperfeiçoamentos) serem dadas, não decorrem necessariamente novos progressos. O intervalo entres progressos disponíveis e os novos avanços que podem decorrer deles é muito variável: aperfeiçoamentos podem ser acelerados, retardados ou ter suas conexões com progressos futuros ignoradas.

Entre um progresso e outro há intervalos que possibilitam e exigem agenciamentos. O Prospecto especifica como a capacidade de agenciar os progressos entra em cena: "Essas observações sobre o que o homem foi, sobre o que ele é atualmente, levarão em seguida aos meios de garantir e acelerar os novos progressos que sua natureza lhe permite ainda esperar" 48 . Agenciar é o modo de operar da arte social como passagem da teoria à prática. A arte social combina elementos dados para

segundo uma probabilidade cada vez maior." (FRICK, Condorcet et le problème de l'Histoire, p. 357). Contudo essa forma de ver não pode deixar de levar em conta o modo como a perfectibilidade constitui a silhueta original do humano.

45 Por exemplo, pode-se mencionar a passagem do Prospecto onde se mostra que o modo como a necessidade de um chefe faz surgir a autoridade política decorre do modo como as primeiras instituições que foram surgindo dependeram do progresso da linguagem, pois sem a formação de uma língua comum, ordens, comandos e leis não poderiam ser estabelecidas. Há uma diferenciação nos progressos levados a cabo por um indivíduo capaz de perceber uma necessidade e produzir uma inovação e os avanços que decorrem da interação coletiva. A invenção da língua, diferentemente da invenção do arco (por um gênio), foi obra de toda uma sociedade (CONDORCET, Esquisse d'un tableau historique des progrès de liesprit humain, p. 93).

46 Os aperfeiçoamentos da humanidade se devem a necessidade de sensações e ideias novas capazes de incrementar a vida coletiva, o que nem sempre encontra situação favorável: “(...) a incerteza e a dificuldade de prover a própria subsistência, alternação necessária entre uma fatiga extrema e um repouso absoluto, não deixam de forma algum ao homem o momento de descanso, no qual ao se abandonar em suas ideias, ele pode enriquecer sua inteligência com combinações novas. Os meios de satisfazer suas necessidades são muito dependentes do acaso e das estações para estimular uma indústria da qual os progressos possam ser transmitidos, e cada um se limita a aperfeiçoar sua habilidade ou sua destreza pessoal" (CONDORCET, Esquisse d'un tableau historique des progrès de l'esprit humain, p. 80).

${ }^{47}$ CONDORCET, Esquisse d'un tableau historique des progrès de lèesprit humain, p. 80.

${ }^{48}$ Id., ibid. 
produzir novos arranjos nos âmbitos políticos e institucionais. $\mathrm{O}$ agenciamento, do qual o cálculo combinatório é um instrumento, caracteriza-se pela identificação das oportunidades dadas pelos progressos pretéritos e a remoção dos obstáculos aos novos aperfeiçoamentos. Entre um progresso e outro há um espaço de manobra, capacidade de prever novos progressos, oportunidade de fazer novas combinações, de acelerar aperfeiçoamentos. É nesse intervalo que opera a arte social.

A arte social exige conhecer, avaliar e estimar as tendências para melhor intervir na marcha dos progressos. Semelhantemente a um jogo ${ }^{49}$, isso é um processo instável. Os avanços do espírito humano alteram as condições do exercício da perfectibilidade, especificamente os modos de efetivação dos direitos, e a percepção do justo e do injusto ${ }^{50}$. Cada contexto exige critérios adequados para se avaliar os progressos do espírito humano da época e a maneira como eles alteram a própria constituição do homem e, por conseguinte, a compreensão de seus direitos naturais.

A conexão dos direitos dos indivíduos com a perfectibilidade da natureza humana afeta o modo como a justiça é identificável. As últimas questões postas na Décima Época do Prospecto referem-se à esperança nas possibilidades de intervenção na natureza humana (faculdades físicas, intelectuais e morais) disponibilizadas pelas descobertas científicas e pela instrução pública ${ }^{51}$. Por ser perfectível coletivamente, aponta Condorcet, o homem tem sido capaz de, no bojo de seu progredir, descobrir-se como portador de direitos naturais e reconhecer nisso o critério mais elevado para conhecer e avaliar o que é justo ou não (verdadeiro ou falso) em relação às intervenções que faz sobre si mesmo. De qualquer nodo, o direito ao aperfeiçoamento é o mais fundamental, sem ele, os demais poderiam tornar-se, com o tempo, inadequados.

A perfectibilidade indefinida do ser humano e, correlatamente, dos direitos naturais são incorporados (via instrução pública) como valores guias da razão comum, instância que passa a ponderar sobre o justo e o injusto. Dessa descoberta, realizada apenas na Nona Época do Prospecto, deduz-se que doravante seriam impossíveis retrocessos, decadência moral e ruptura civilizacional, pois os óbices dos progressos passaram a ser conhecidos e combatidos, dado o poder civilizatório (perfectível) da instrução pública. O aperfeiçoamento da forma de identificar e difundir o progresso chegara então a um momento que o torna um valor irrecusável.

Quando a perfectibilidade é reconhecida como um valor intrínseco e como uma escala para tudo avaliar, o que obstaculiza o progresso (das luzes) passa a ser tomado como um mal ${ }^{52}$. A exigência de progresso, até então sendo realizado de modo inconstante e incerto, marcado por

\footnotetext{
49 "Se não se pode tudo prever, não mais que o jogador de cartas pode prever, com segurança, as partidas que ele joga, poder-se-á pelo menos escolher as 'combinações' que têm as maiores chances de produzir os efeitos visados e eliminar as que têm possibilidades contrariá-los" (FRICK, Condorcet et le problème de l'Histoire, pp. 346-7) 50 "Fixamos já regras precisas para escolher de modo seguro entre o número quase infinito de combinações possíveis, capazes de respeitar os princípios de igualdade e dos direitos naturais, as que mais asseguram a conservação de tais direitos? (CONDORCET, Esquisse d'un tableau bistorique des progrès de l'esprit bumain, p. 283)

${ }^{51}$ CONDORCET, Esquisse d'un tableau historique des progrès de lesprit humain, p. 295.

52 CONDORCET, Vie de Turgot, p. 207.
} 
avanços, estagnações e mesmo retrocessos, torna-se, na última época do Prospecto, programática e coletivamente intencional. Efetivos mecanismos contra a decadência passam a ser constituídos (criação de academia de ciências, instrução pública, eleições livres, declaração de direitos anteposta à constituição, revisões periódicas das leis, liberdade de imprensa, etc.). A efetividade da lei (do imperativo) do progresso se expressa nas instituições racionais, ao mesmo tempo, resultantes e garantidoras do aperfeiçoamento humano.

A centralidade da ideia de progresso aparece no seu poder de produzir consenso em torno do que fazer. Nesse sentido, em Condorcet, a noção de perfectibilidade humana, base do progresso, foi sendo ajustada operacionalmente para permitir a identificação de critérios racionais orientadores das decisões coletivas sobre o melhor a ser feito. A política é apresentada, antes de tudo, como uma forma de agenciamento coletivo da perfectibilidade. Esse agenciamento caracteriza-se sobretudo pelo modo de operar a passagem dos progressos passados para os progressos futuros. Contudo, para o autor, a razão comum ou colegiada também está sujeita a perfectibilidade em seus procedimentos para agenciar o progresso, sem o que ela perde sua legitimidade.

\section{Considerações finais}

O progresso da própria perfectibilidade (e a perfectibilidade do progresso) junto à naturalização do espírito humano fundamentam a imanência da normatividade. A condição de perfectibilidade do ser humano dá as ciências morais e políticas o objeto, e as exigências dessa condição, a de buscar o melhor, oferecem-lhes a finalidade. Isso reflete no modo de Condorcet compreender a política. Ele não propõe a política como uma mera prática de instanciação das diretrizes de um design conhecido ou concebido de modo privilegiado pelos arautos do progresso, mas como uma forma de agenciamento que exige acurada articulação entre ciência e arte, ou seja, teoria e prática. Nesse sentido o aspecto prático da razão, na perceptiva de Condorcet, é lúdico. O Prospecto expressa uma aposta (uma decisão e um querer racional) no progresso, pois as probabilidades estão a seu favor. Esse otimismo baseia-se no postulado de que ao se conhecer as tendências do progresso, são adquiridos recursos para se atuar sobre o mesmo ${ }^{53}$.

A descoberta - surgimento da esperança - do progresso necessário e indefinido foi um evento no bojo da civilização europeia do Século Dezoito ${ }^{54}$, como é apontado na Nona Época do Prospecto. Desde então, o valor universal da humanidade passa a ser identificado com o imperativo

\footnotetext{
53 Condorcet fala em tendências e probabilidades. Não se trata, portanto, de "descobrir leis sociais, mas de contentar-se com tendências para o passado e probabilidade para o futuro." (KRYNSKA, Entwicklung und Fortschritt nach Condorcet und A. Comte, p. 74).

${ }^{54} \mathrm{O}$ significado do progredir é dado pela perfectibilidade manifestada na Europa que passa a ser um guia para os demais povos. Mas isso tem menos a ver com "etnocentrismo", por parte de Condorcet, do que com a forma como ele compreendeu a imanência dos valores universais, o que seria objeto de uma nova investigação.
} 
do progresso, isto é, a necessidade de mudar o que é irracional e injusto, o que de um modo ou de outro tende a ser feito, em consequência da aceitação do ser humano como perfectível.

A perfectibilidade, como seu viu, é uma matriz normativa de princípios e critérios de escolhas. Mas o valor do progresso é autorreferente. O progresso submete tudo ao seu registro, até a si mesmo. Nenhum valor, exceto a exigência do melhor, é alçado como peremptório, admitindose mesmo que o modo de identificar a legitimidade de uma norma depende dos constantes progressos do espírito humano. Seriam falsas (ilegítimas) as decisões que não levassem em conta tais progressos e dogmatizassem ou tornassem objeto de adoração alguma norma, referente tanto à forma quanto ao conteúdo do pronunciamento epistêmico/normativo da arte social. A exigência do melhor está condicionada ao aperfeiçoamento das formas de aferi-lo.

Condorcet apresenta um quadro de como será a humanidade libertada do "império do acaso", sabendo bem jogar com este, e livre dos inimigos do progresso, de modo que nada a desviaria seriamente da rota da verdade, da virtude e da felicidade. O como será é uma base diversa do estabelecimento hipotético do como idealmente seria melhor deduzido da mera natureza humana abstrata ou da construção utópica e dogmática de um dever ser que não se engendra no próprio processo definidor do possível e desejável a partir do patrimônio de progressos até então disponíveis.

Esse como será é dado por um acurado levantamento dos percursos do espírito humano e de uma prospecção combinatória sobre o que ele melhor pode continuar realizando. No quadro da Décima Época, avalia-se - no sentido de conhecer, mensurar, prospectar combinações viáveis e legítimas - o já realizado e o que é (deve ser) efetível. É na passagem de um para o outro que o progresso se apresenta como norma. O Prospecto mostra como a perfectibilidade humana deve ser conhecida e os progressos futuros podem ser agenciados conforme o princípio de sempre escolher o que vai produzir aperfeiçoamentos condizentes com o que a humanidade foi descobrindo como valor inerente a sua natureza perfectível. O como será desponta-se do conhecimento, é uma noção epistemológica do normativo.

A "lei" do progresso, para o autor, sofre refrações, quebras e desvios. A necessidade do progresso não implica que ele tenda a ocorrer aos "trancos e barrancos", ou melhor, de um modo ou de outro, como um processo independente da vontade esclarecida dos indivíduos. Muito menos ele resulta de uma fria e elitizada modelização da política sem levar em conta o consentimento dos que são afetados por ela. A ideia de progresso em Condorcet guarda uma força normativa mediadora entre o parecer rigoroso da academia e o pronunciamento dos cidadãos. Frente à tensão entre fatos, tendências desejáveis e valores conflitantes apresenta-se uma escala de aferição dada pela declaraşão de direitos, por sua vez fruto de constantes reflexões, correções e aperfeiçoamentos. 


\section{CONDORCET'S NORMATIVE CONCEPTION OF PROGRESS}

Abstract: The text shows how, in Condorcet's philosophy, social art, political agency, is guided by the norm of progress. It is argued that the normativity associated with the concept of progress, as fact and value, is immanent, that is, it is not defined as an idealized ought or a model of perfection for decision, but what will be better to do in a context of accumulated and to be achieved improvements.

Keywords: Condorcet - social art - progress - normativity - immanence.

\section{Referências bibliográficas:}

ALLEN, A. The End of Progress: Decolonizing the Normative Foundations of Critical Theory. Columbia University Press, 2016.

BARDÈCHE, M. Nuremberg ou la Terre Promise. Paris: Les Sept Couleurs, 1948.

BINOCHE, B. (Org.) L'bomme perfectible. Paris, Champ Vallon, 2004.

BOARINI, S. Turgot, Condorcet. Les Lumières face au progrès. Dix-buitième siècle, 2011/1 (nº 43), p. 523-540.

CONDORCET, Marquis de. Discours de réception a l'Academie Française. In: Oeuvres, Tome I. Stuttgard: Friedrich Frommann Verlag (Reimpressão), 1968.

Vie de Turgot. In: Oewrres, Tome V. Stuttgard: Friedrich Frommann Verlag (Reimpressão), 1968.

Fragment de l'histoire de la Xe époque In: Oewures, Tome VI. Stuttgard: Friedrich Frommann Verlag (Reimpressão), 1968.

Sur le sens du mot Révolutionnaire. Oewvres, Tome XII. Stuttgard: Friedrich Frommann Verlag (Reimpressão), 1968.

Esquisse d'um tableau des progrès de l'esprit bumain. Paris: Flammarion, 1988.

DAGEN, J. L'bistoire de l'esprit humain dans le pensée francaise: de Fontenelle à Condorcet. Paris: Klincksieck. 1988.

D’HOLBACH, P. H. Système de la nature ou des lois du monde physique et du monde moral. Edição eletrônica, Chicoutimi, 2007.

EGE, R., IGERSHEIM, H. \& LE CHAPELAIN, C. Transcendental vs Comparative Approaches to Justice: A Reappraisal of Sen's Dichotomy. The European Journal of the History of Economic Thought. Volume 23, 2016 - [Published online: 25 Jun 2014] 
FORST, R. Kontexte der Gerechtigkeit: Politische Philosophie jenseits von Liberalismus und Kommunitarismus. Frankfurt am Main: Suhrkamp, 1994.

FRICK, J-P. Condorcet et le problème de l'Histoire. In: Dix-huitième Siècle, nº18, 1986. Littératures françaises. pp. 337-358.

HERMAN, A. The Idea of Decline in Western History. New York: The Free Press, 1997.

HONNETH, A. Das Recht der Freiheit: Grundriß einer demokratischen Sittlichkeit. Berlin: Suhrkamp Verlag, 2011.

IGGERS, G. The Enlightenment Idea of Progress Revisited. In: ALMOND, Gabriel, CHODOROW, Marvin; PEARCE, Roy (Orgs.) Progress and its Discontents. Berkeley: University of California Press, 1982.

KRYNSKA,S. Entwicklung und Fortschritt nach Condorcet und A. Comte. Berne: Buch druckeri Scheitlin, Spring Cie., 1908.

POPKIN, R. Novas considerações sobre o papel do ceticismo no Iluminismo. Tradução de Klebiano Barbosa de Souza e Paulo Jonas de Lima Piva. In: Sképsis, ano IV, n.6, 2011.

ROTHSCHILD, E. Condorcet and the Conflict of Values. The Historical Journal. Vol. 39, No. 3 (Sep., 1996), pp. 677-701.

SEN, A. The Idea of Justice. Harvard University Press, 2009.

SHEEHY, P. Moral Facts. Richmond Journal of Philosophy, 12, Spring, 2006.

WALDINGER, R. Condorcet: The problematic nature of progress. In: ROSENFELD, L. (Ed.) Condorcet Studies 1. Atlantic Highlands, NY: Humanities Press, 1984. pp. 117-129.

WILLIAMS, David. Progress and the Empirical Tradition in Condorcet. Journal of French and Francophone Philosophy. Vol 4, No 1, 1992. 